\title{
Social Conventions and Issues of Space for Distributed Collaboration
}

\author{
Hillevi Sundholm \\ Dept. of Computer and Systems Sciences \\ Stockholm University/The Royal Institute of Technology \\ Forum 100, S-164 40 Kista, Sweden \\ hillevi@dsv.su.se
}

\begin{abstract}
We followed the work of an international research network that holds regular meetings in technology-enhanced environments. The team is geographically distributed and to support its collaborative work it uses a set of technical artifacts, including audio- and videoconferencing systems and a media space. We have been studying some of the techniques and social conventions the team develops for its collaboration, and different aspects of what it mean to be located in a shared but distributed workspace. Our approach has been to analyze the initiatives and responses made by the team members. Over time the group created conventions; e.g. the chair introduces team members participating only by audio and members turn off their microphones when not talking. The latter convention led to the side effect of faster decision making. We also identified two characteristics, implicit excluding and explicit including, in a situation where the majority of the team members were co-located.
\end{abstract}

Keywords: Social conventions, Distributed Collaboration, Co-location, Shared Workspace, Group-to-group collaboration.

\section{Introduction}

Although current technologies offer many different possibilities for communicating, interacting and sharing information simultaneously at a distance, people still prefer to work at the same place using a common collaborative space [32]. Computer-mediated communication may be efficient for disseminating information but for decisionmaking it is rarely if ever more effective than face-to-face meetings [4]. Moreover, the frequency and quality of communication declines when the distance increases between participants' offices [22]. This finding has recently been supported in an experimental study [7]; the authors concluded that researchers in the field of Computer-Supportive Cooperative Work (CSCW) need to pay more attention to the design of technology to overcome social and geographical distance. Group-to-group collaboration, which is becoming increasingly common, also deserves more study as it places different demands on the participating individuals and on the design of the systems, compared to individual distance collaboration [28].

In this paper we present a study with a group of researchers who regularly engage in geographically distributed meetings. The team uses a set of technical artifacts to 
support its collaborative work, including large wall displays and a media space. An important characteristic of the setting, one that makes the situation more complex, is that both video- and audio conferences have been used as communication channels. In this area of research many studies focus on systems and users, and on the specific design of shared tools for distributed collaboration [14, 18, 25, 31, 41]. However, few long-term empirical studies have aimed at furthering our understanding of teamwork in these settings. In a previous paper [37] we looked at how the team members created mutual understanding about the current situation, how available artifacts mediated the collaboration, and the role of visual representations. We investigated those issues by looking at the turn-taking between both the team members and when using the shared media space, in addition to which communication channel they use (i.e. video and/or audio). We saw that in this multi-channel setting the participants often have to clarify who is attending, and those who are only present on audio risk being left out of conversation. Another outcome was that the communication space is limited; when many want to participate in the communicative activity, it becomes harder to make a successful initiative.

In this paper we investigate some of the techniques and social conventions the team members developed in order to collaborate and to handle situations that arose. So far social conventions have received too little attention in CSCW [27]. We also investigate what it means to have a "distributed" location, that is, to operate in a shared but distributed workspace. Initiative-Response Analysis [26] helped us study the interaction between the team members.

\section{Related Work}

In all collaborative work, an important issue is how to maintain, at least to some degree, both a shared view and a shared understanding so that the team members can perform the work and reach common goals. In long-term collaboration the team members must establish and maintain a shared awareness of their actions, plans, goals and activities [29]. Face-to-face interaction provides people with many contextual cues such as facial expressions, body postures and gestures that guide them as they interpret others' communication and interact with them [16]. Some or all of these cues disappear in distributed meetings, depending on which media are used to enable communication. Video is shown to be especially important in distributed collaboration if the participants do not have the same native language: the picture supports them in showing their understanding through facial expressions and gestures [40]. However, it is often more important to share the view of the work than see each other [12]: by demonstrating their activity to the other team members they can efficiently establish a shared understanding within the group [15].

\subsection{Social Conventions}

All actions are situated and all communication is embedded in the present and in the past. This means that we cannot separate an action from the context where it takes place; we also make use of earlier experiences to handle a current situation. We have to learn which verbal and nonverbal behaviors are appropriate in which situation [11], 
and we must understand what the current context means; this shared knowledge is essential if we are to be socially competent.

At least two techniques help people to coordinate their interaction: making explicit agreements and using conventions [10]. The conventions are normative and guide people towards the correct and acceptable behavior, as well as predicting group behavior [27]. The explicit conventions (as well as prescribed procedures) mediate the articulation of cooperative activities [34].

The community members share the conventions, which help them to coordinate action and avoid problems [24], because they make the social system more stabile, efficient, and coherent [5]. An example of a convention in our culture is that we greet one another with our right hands when we first meet. Conventions are arbitrary in the sense that they usually result from historical coincidences [10, 24]; for example, we greet with the right hand and not with the left [10].

Whereas Clark [10] makes the distinction between explicit agreements and conventions, Becker and Mark [5] differentiate between explicit and implicit social conventions. The explicit conventions are agreed upon, while the implicit ones are embedded in the social practice. When newcomers join a group or community they must become aware of the implicit social conventions [5].

Similar to our notion of social conventions Schön [33] talks about norms as a contract of shared rules between actors that govern their behavior. Those norms consist of both formal and informal understandings of what to expect from each other. These reciprocal expectations are often important in practice, e.g. when designing systems: the user and designer must share their expectations about the kinds of communications the system needs to handle in various kinds of situations [36].

Becker and Mark [5] compared three different virtual environments, focusing on the role social conventions play in communication and how the on-line systems supported those conventions. Their findings indicate that people use the same social conventions in those kinds of settings as in face-to-face interactions; however, they supported and/or expressed those conventions differently, depending on the media. For example, when team members had to leave a conversation, they signed off by saying goodbye, and included an explanation if they had to leave early. Social conventions are important for creating common understanding of behaviors, and therefore, they are important for maintaining the consistency of the space as a social system [5].

In a longitudinal study lasting about 4 years, Mark [27] followed a group of workers in a German ministry who used an electronic system to share and coordinate their work between different units and cities. The distributed groups failed to develop any normative conventions, partly because it takes time and a certain amount of communication to recognize each others actions and behaviors. As the co-workers were geographically distributed they could not create conventions implicitly; instead the local subgroups created their own conventions, which never became common to the larger group. They could have avoided this situation if they had committed to creating explicit conventions, or if the system had given them more feedback. Feedback functions in two ways: it can provide information about appropriate behavior, and/or it can reinforce certain behaviors [26].

Gay and Hembrooke [13] revealed the limitations on communications in a study of a tool that enabled students to view and discuss art online. The major problems they 
encountered were knowing when and where to make contributions because normal social conventions and cues were restricted. The lack of instant feedback may disturb the flow of communication, and the lack of visual cues, like facial or physical expressions, makes it difficult to interpret inactivity or silence.

\subsection{Distributed Collaboration: Being Co-located, Being Distributed}

Many researchers have studied the role of audio only in a distributed setting (e.g. [17]) and the role of video for remote collaboration (e.g. [19]). However, few have studied multi-channel or mixed-media settings, a complex situation where team members often are unequally distributed [9]. In an experimental study Bos et al. [8, 9] looked at teams that were partly co-located and partly distributed; a total of 130 subjects participated, divided into thirteen groups. Each group engaged in five sessions lasting 15-20 minutes each, in which half the group was co-located and half was distributed. Their task was to play a game that required them to buy and sell "skills", and each player had a special skill to offer. To succeed well in the game the player had to sell to and buy from both co-located and distributed participants. Their results show that the co-located players failed to pay enough attention to the distributed ones, a phenomenon called 'collocation blindness' [8]; in turn the distributed members created an 'in-group' with one another [9]. However, the distributed players were still able to do very well on the game if they had skills that were scarce in the co-located group [8].

\section{Method}

\subsection{General Description of Corpus}

Between April and December of 2004 we followed nine meetings of an international research network that consists of ten laboratories spread out across Europe and North America. The teams are not working on a common project but they share interests and use these occasions to share information and expertise, through discussions and presentations.

Every month they have a geographically distributed meeting. They use a multiplex videoconferencing system to transmit video and audio; an audio conference system is available in case the video link fails. They also have access to a shared media space and a wiki ${ }^{1}$ website to share information; both are accessible on the Internet. They use the wiki website mainly to store internal information about the team members and the labs, along with meeting dates and agendas; this information is primarily used between the meetings. General information is also available to individuals who visit the page. The media space, on the other hand, is used as an information resource, a place where they can upload and download documents such as their presentations and working documents. The media space is used during the meetings and functions as a shared virtual workspace where everyone who is logged in can work simultaneously. One restriction is that only one person at a time can manipulate a document. To

\footnotetext{
${ }^{1}$ Wiki is a type of server software that allows invited users to create, add and remove web page content while using any browser (http://wiki.org/wiki.cgi?WhatIsWiki).
} 
handle meta-communication and provide silent support during the meetings they use an instant messenger (IM), to which they log on before the meetings begin.

The laboratories use two screens to display the information, and usually at least one of the screens is large: one screen shows the team members who are present on video and the other displays the shared media space. Figure 1 shows the meeting situation in one of the labs; the video connections are shown on the left screen and the shared media space on the right one.

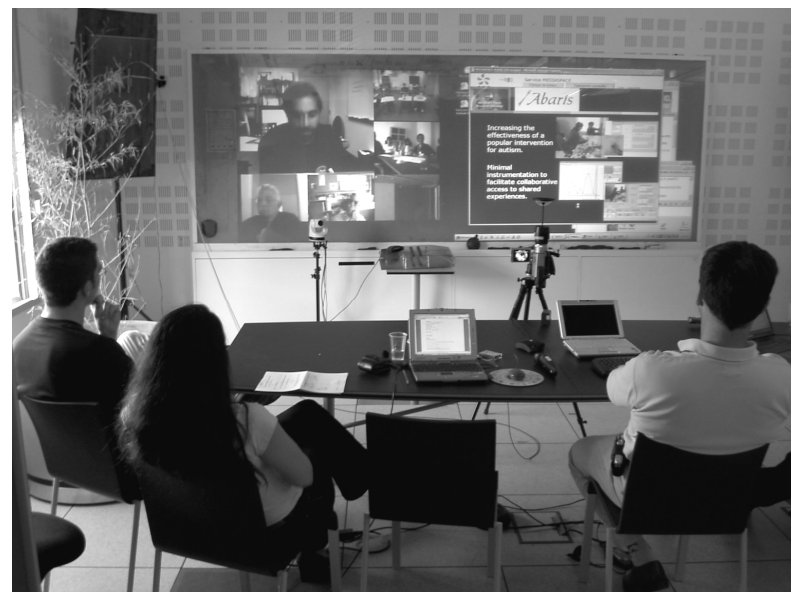

Fig. 1. Meeting situation

The number of participating teams may differ from one meeting to the next. During the meetings we followed, 4 to 7 teams were present at a given videoconference, and sometimes one or more teams were present on audio. Anywhere from 11 to 19 individual team members have participated in various meetings. The meeting time is a compromise between the labs since they are located in different time zones. Depending on which labs are connected, the local time may differ by as much as 11 hours.

The meetings have both a formal and an informal character. They are formal in the sense of having a clear meeting time, a chair, an agenda, and a procedure for getting connected. But they are also informal: the team members, specially the lab managers, know each other very well and the meetings function as a way to keep in touch. The meetings are divided into two parts. During the first part, for which 45 minutes is reserved, all the labs are to be connected and technical issues are discussed. The second part, which lasts about an hour, is the research seminar, where network activities and research are presented and discussed.

\subsection{Data Collection}

All meetings were recorded at Laboratory of Design for Cognition, EDF R\&D, one of the network members. We used two to four fixed cameras in order to cover different angles in the space: one camera for the shared media space, one for the screen that 
shows the videoconference picture, and finally one or two for the local space (as illustrated in Figure 1). We also used a $360^{\circ}$ angle camera and ceiling cameras to position the local participants, and at two of the meetings one of the participants used a wearable camera [23]; however, we do not include data from those cameras in this analysis. The data we analyze here consists of about 18 hours of video recordings. We also handed out or e-mailed questionnaires before and after the meetings. The questionnaires helped us understand the personal objectives of the people attending and asked for suggestions on how to improve the meetings.

\subsection{Data Analysis}

Our work is based on Initiative-Response Analysis [26], which analyses dialogue or multiparty communication (a neutral term is 'communicative activity'), in terms of initiatives and responses. The unit of analysis is the turn, and it is a useful model for understanding the global aspects of communicative activities where the turns are relatively short. We have focused especially on how people take the initiative to introduce a new episode [20]. The initiative is an attempt to request, claim or dominate and it refers forwards; the response refers backwards, and can be more or less immediate. In contrast to many other theorists, such as [35], Linell and Gustavsson [26] do not talk about 'follow-up moves'. Instead they mean that every utterance can be classified as either an initiative or a response. They developed a 6level system for evaluating how strong or weak the initiatives and responses are, but for our purposes we have restricted the analysis to the following four: strong initiative (introducing a new topic and explicitly requesting a response), weak initiative (introducing new content by claiming something that possibly requires a response), extended response (response that adds new content to the preceding turn, or implicitly asks for a response) and minimal response (response without any initiative).

Interaction Analysis [21] has also influenced our analysis, particularly the following four foci: 'Beginning and Endings', 'Turn-taking', 'Trouble and Repair', and 'The Spatial Organization of Activity'.

We transcribed five of the meetings using regularly indicated time stamps. During the transcription and analysis, we noted the most interesting episodes. The notes covered a wide range, from what was monitored and manipulated on the displays to social interaction between the team members. We re-transcribed the parts we thought to be most interesting, adding detailed information, including the exact time stamps for beginnings and endings. We divided the excerpts following the work of [30], but modified the format slightly. Our 'Transcript of Interaction' does not indicate the times of pauses in the talk, and our 'Characteristic of Action' clarifies the action more abstractly: Is the turn is an initiative (I) or a response (R), and which line (L) does it refers to? In addition we categorized each turn in line with the work of Baker et al. $[2,3]$. The categories we use in this report are Social relation, Interaction management, and Task management. By social relation we mean interaction concerned with managing the social relations and verbalizing the situation (the latter is not included in [2, 3]). Interaction management concerns the interaction itself: coordination, establishing contact, understanding, topic shifting etc. Finally, task management is about planning the task and making progress on it. 
In the excerpts presented in the results all names were changed and personal information replaced by ellipses ' $[\ldots .$.$] '.$

\section{Results and Analysis}

For this analysis we have chosen to illustrate two different situations. In the first one, which represents the most common meeting situation, the labs are geographically distributed from each other; in these situations the difference is whether the teams are present on both video and audio, or only on audio. In the other situation, the "April meeting", most of the team members were present at a conference venue in Vienna (i.e. outside the laboratories), and only two teams ${ }^{2}$ with a total of three participants were present on video from their labs. ${ }^{3}$

\subsection{Being Present: Introduced, Forgotten and Re-introduced}

Each team member can only completely view his or her own local situation, that is, who is attending (locally), what they have access to (e.g. the media space and the IM) and the quality of sound and picture. Normally the organizing lab, which also helps the other labs to connect, is the one that can have the best overview of the situation. For this reason the convention is that the chair explicitly shares his knowledge about the presence of the participants with the other team members. For this reason the convention is that the chair explicitly shares his knowledge about the presence of the participants with the other team members. For those participating by audio, it is especially important to be recognized as present and also to know who are present on video. In Excerpt 1 we see how the chair introduces a team member (present on audio) who joined the meeting late.

Excerpt 1. June meeting: Introduction to the other team members

\begin{tabular}{|c|l|l|l|}
\hline $\begin{array}{l}\text { Time } \\
\mathbf{0 : 1 9 : 4 5}\end{array}$ & $\begin{array}{l}\text { Person, team, } \\
\text { mode }\end{array}$ & Transcript of Interaction & $\begin{array}{l}\text { Characteristics of } \\
\text { Action }\end{array}$ \\
\hline 1 & $\begin{array}{l}\text { Olivier, \#1, } \\
\text { video }\end{array}$ & $\begin{array}{l}\text { "I, I think hmm... Andy? Did you join us, } \\
\text { Andy?" }\end{array}$ & $\begin{array}{l}\text { Strong I. Interaction } \\
\text { management }\end{array}$ \\
\hline 2 & $\begin{array}{l}\text { Andy, \#9, "Yes, yes I am here." } \\
\text { audio }\end{array}$ & $\begin{array}{l}\text { Minimal R to L1: } \\
\text { Interaction } \\
\text { management }\end{array}$ \\
\hline 3 & $\begin{array}{l}\text { Olivier,\#1, } \\
\text { video }\end{array}$ & $\begin{array}{l}\text { "Yes, you are here, okay... because the others } \\
\text { were not aware that, that you had come in, so... I } \\
\text { was the only one to know so I share the news." }\end{array}$ & $\begin{array}{l}\text { Extended R to L2: } \\
\text { Social relation }\end{array}$ \\
\hline 4 & $\begin{array}{l}\text { Andy, \#9, "Well, thank you." } \\
\text { audio }\end{array}$ & $\begin{array}{l}\text { Minimal R to L3: } \\
\text { Social relation }\end{array}$ \\
\hline
\end{tabular}

End of Excerpt: 0:19:59

By using a strong initiative (line 1) we see that Olivier, the chair, introduced Andy to the others at the meeting. But the convention of introducing team members early on in the meeting does not guarantee that each participant will be remembered throughout. Excerpt 2 illustrates how a team member who is participating only on audio has been forgotten.

\footnotetext{
${ }^{2}$ A third lab was connected to handle the technical support.

${ }^{3}$ This situation is what Bos et al. [8] call 'partially-distributed groups'.
} 
Excerpt 2. June meeting: Forgotten in the audio

\begin{tabular}{|c|l|l|l|}
\hline $\begin{array}{l}\text { Time } \\
\mathbf{0 : 4 6 : 4 2}\end{array}$ & $\begin{array}{l}\text { Person, team, } \\
\text { mode }\end{array}$ & Transcript of Interaction & $\begin{array}{l}\text { Characteristics of } \\
\text { Action }\end{array}$ \\
\hline 1 & $\begin{array}{l}\text { Olivier, \#1, "By the way, Thomas, are you still there?" } \\
\text { video }\end{array}$ & $\begin{array}{l}\text { Strong I: Interaction } \\
\text { management to L2: } \\
\text { audio }\end{array}$ & $\begin{array}{l}\text { Minimal R to } \\
\text { Interaction } \\
\text { management }\end{array}$ \\
\hline 3 & $\begin{array}{l}\text { Olivier, \#1, "I am still here, yeah." } \\
\text { video }\end{array}$ & $\begin{array}{l}\text { "Okay, because I realized we have forgotten } \\
\text { you for a while." }\end{array}$ & $\begin{array}{l}\text { Weak I: Social } \\
\text { relation }\end{array}$ \\
\hline
\end{tabular}

\section{End of Excerpt: 0:46:49}

When Olivier realizes that Thomas had been forgotten, he assures the others of his presence by using a strong initiative (line 1). Our interpretation of these two situations is that someone participating only on audio may find it very difficult to make an initiative unless they have a direct request from someone who is already part of the communicative activity ${ }^{4}$ (compare this to the analysis in section 4.3 ). Here, the convention of having the chair introduce audio-only participants and continue to check on their presence helps to overcome the problem to some extent.

\subsection{Making Decisions Across Spaces}

A meeting situation that includes up to seven teams at the same time ${ }^{5}$ can be demanding for all the participants. It requires that they be focused and strict in the way they interact and that they all minimize disturbances during the meetings. Over time they have developed several conventions for handling the meeting situation. One convention is using an instant messenger to handle meta- communication, for example to say hello when connecting late or to inform others about connection problems. This allows them to communicate without interrupting the ongoing discussion. They also have created an explicit convention of turning off the microphone when not speaking, in order to minimize the risk of transmitting unwanted sounds to the others or causing an echo. Excerpt 3 illustrates that turning off the microphone can change the way people contribute to the conversation and make decisions. The team members are discussing whether they should exchange their IM system for another one and if so, to what other one.

Excerpt 3. November meeting: Decision-making

\begin{tabular}{|c|l|l|l|}
\hline $\begin{array}{c}\text { Time } \\
\text { 0:54:00 }\end{array}$ & $\begin{array}{l}\text { Person, site, } \\
\text { mode }\end{array}$ & Transcript of Interaction & $\begin{array}{l}\text { Characteristic of } \\
\text { Action }\end{array}$ \\
\hline 1 & $\begin{array}{l}\text { Olivier, \#1, } \\
\text { video }\end{array}$ & $\begin{array}{l}\text { "All right, what, what I suggest is that some, } \\
\text { somebody takes the lead on this, on this issue and } \\
\text { takes the decision technically and, and with whoever } \\
\text { they want, but that someone takes a decision. I think } \\
\text { you on your side, Peter, you are probably the ones } \\
\text { management } \\
\text { messaging system, if I... You seem to have tried a lot } \\
\text { of things, so maybe somebody could just decide, and } \\
\text { we'll, we'll just take your solution." }\end{array}$ & \\
\hline
\end{tabular}

\footnotetext{
${ }^{4}$ Another relevant aspect that we have argued for earlier is that the communication space is limited [37].

${ }^{5}$ More is possible, but this we have not seen during these nine meetings.
} 
Excerpt 3. (continued)

\begin{tabular}{|c|c|c|c|}
\hline 2 & $\begin{array}{l}\text { Peter, } \quad \# 2, \\
\text { video }\end{array}$ & $\begin{array}{l}\text { "Okay, we, we just talked about this here locally with } \\
\text { the microphone off, ha-ha, and what we can do is, we } \\
\text { will, Mattias will go to the wiki website, the [...] } \\
\text { website, and put up a little section on, on IM clients } \\
\text { and with links to recommended systems for both } \\
\text { Macintosh and, and Windows users. Do we have any } \\
\text { people who are using Unix, Linux or anything?" }\end{array}$ & $\begin{array}{l}\text { (Less than } 1 \mathrm{~s} \text {. } \\
\text { between } \mathrm{L} 1 \text { and } \\
\text { L2) } \\
\text { Extended } \mathrm{R} \text { to } \\
\text { L1: Task } \\
\text { management }\end{array}$ \\
\hline 3 & $\begin{array}{l}\text { John, } \\
\text { video }\end{array}$ & "Yes." & $\begin{array}{l}\text { Minimal } \mathrm{R} \text { to } \mathrm{L} 2 \text { : } \\
\text { Task management }\end{array}$ \\
\hline 4 & $\begin{array}{l}\text { Peter, } \\
\text { video }\end{array}$ & $\begin{array}{l}\text { "Okay, we'll, we'll include a link to, to people, for } \\
\text { solutions for those people as well." }\end{array}$ & $\begin{array}{l}\text { Extended R to L3: } \\
\text { Task management }\end{array}$ \\
\hline
\end{tabular}

End of sequence: 0:55:00

Olivier's strong initiative in line 1 gets a quick response from team \#2 in line 2 since Peter is able to discuss it in parallel with his local team members. Turning off the microphone enabled them to accept the request quickly, and meanwhile manage their local interaction (who will do what). Line 2 ends with a request from Peter so that his team can fulfill the undertaking. The whole sequence takes one minute.

At the April meeting, in Vienna, the group made two formal decisions that needed approval from all the others. Excerpt 4 shows how they made the first decision.

Excerpt 4. April meeting: Decision-making

\begin{tabular}{|c|c|c|c|}
\hline $\begin{array}{l}\text { Time } \\
\text { 0:52:17 }\end{array}$ & $\begin{array}{l}\text { Person, team, } \\
\text { mode }\end{array}$ & Transcript of Interaction & $\begin{array}{l}\text { Characteristic of } \\
\text { Action }\end{array}$ \\
\hline 1 & $\begin{array}{l}\text { Olivier, } \\
\text { Vienna }\end{array}$ & $\begin{array}{l}\text { "Let's, let's go on. So we'll have to give an answer } \\
\text { to Anna more formal than... In the way I } \\
\text { understand it you more or less agree on this, or? } \\
\text { More or less?" }\end{array}$ & $\begin{array}{l}\text { Strong I: Task } \\
\text { management }\end{array}$ \\
\hline 2 & $\begin{array}{l}\text { Several } \\
\text { people, Vienna }\end{array}$ & {$[$ Inaudible $]$} & $\begin{array}{l}\text { Simultaneous talk } \\
\text { (2 s.) }\end{array}$ \\
\hline 3 & Aaron, Vienna & "[Inaudible] let's raise your hands." & $\begin{array}{l}\text { Weak I: Task } \\
\text { management }\end{array}$ \\
\hline 4 & Andy, Vienna & "That's a great format!" & $\begin{array}{l}\text { Extended R to L3: } \\
\text { Social relation }\end{array}$ \\
\hline 5 & $\begin{array}{l}\text { Olivier, } \\
\text { Vienna }\end{array}$ & "Yes." [Everybody raising hands] & $\begin{array}{l}\text { Minimal R to L1: } \\
\text { Task management }\end{array}$ \\
\hline 6 & Peter, Vienna & "Yeah, we're okay." & $\begin{array}{l}\text { Minimal R to L1: } \\
\text { Task management }\end{array}$ \\
\hline 7 & $\begin{array}{l}\text { Several } \\
\text { people, Vienna }\end{array}$ & [Inaudible] & $\begin{array}{l}\text { Simultaneous talk } \\
(5 \mathrm{~s} \text {.) }\end{array}$ \\
\hline 8 & $\begin{array}{l}\text { Olivier, } \\
\text { Vienna }\end{array}$ & "What, what about you who are remote? [...]" & $\begin{array}{l}\text { Strong I, related to } \\
\text { L1: Task } \\
\text { management }\end{array}$ \\
\hline 9 & $\begin{array}{l}\text { Michael, \#6, } \\
\text { video }\end{array}$ & "Yeah." & $\begin{array}{l}\text { Minimal } \mathrm{R} \text { to } \mathrm{L} 1 \\
\text { through L8: Task } \\
\text { management }\end{array}$ \\
\hline 10 & $\begin{array}{l}\text { Olivier, } \\
\text { Vienna }\end{array}$ & "Yeah?" & $\begin{array}{l}\text { Minimal I: Task } \\
\text { management }\end{array}$ \\
\hline 11 & $\begin{array}{l}\text { Wolfgang, \#4, } \\
\text { video }\end{array}$ & "Yes." & $\begin{array}{ll}\text { Minimal R } & \text { to } \\
\text { L1/L8: Task } & \\
\text { management } & \end{array}$ \\
\hline 12 & $\begin{array}{l}\text { Unrecognizabl } \\
\text { e } \\
\text { voice, Vienna }\end{array}$ & "Raise your hands!" & $\begin{array}{l}\text { Weak I: Social } \\
\text { relation }\end{array}$ \\
\hline
\end{tabular}


Excerpt 4. (continued)

\begin{tabular}{|c|l|l|l|}
\hline 13 & Nils, \#6, video & "Yes, yes." & $\begin{array}{l}\text { Minimal R to } \\
\text { L1/L8: Task } \\
\text { management }\end{array}$ \\
\hline 14 & $\begin{array}{l}\text { Olivier, } \\
\text { Vienna }\end{array}$ & "Yes, raise your hands, that's correct." & $\begin{array}{l}\text { Extended R to } \\
\text { L1/L8: Social } \\
\text { relation }\end{array}$ \\
\hline
\end{tabular}

End of Excerpt: 0:52:48

In this excerpt we see how the decision was first made among those co-located in Vienna, then by the distributed team members (from line $8 \mathrm{on}$ ). Since the majority of the team members were located in the same physical space they were naturally more able to react when the chair made the strong initiative of suggesting they come to a decision, compared to the distributed ones. The bonds between the team members in Vienna were stronger than between them and the two distributed teams. The distance between the team members was probably also influenced by the fact that the colocated team members started to talk more intensively with each other at two moments (lines 2 and 7), and this further excluded the two distributed teams. In line 8 Olivier used a strong initiative, turning to the distributed team members to include them in the decision-making process.

Their second decision proceeded more smoothly, but the co-located team members were still in focus first, followed by a direct question to the distributed ones.

\subsection{Physical Space Matters: What Does It Mean to Be Distributed?}

In this section we will look more closely into what it means to be participating in a geographically distributed meeting in relation to the mode. In our data we have three conditions: video and audio, audio only, and "co-located" (as in the case in the April meeting). Excerpt 4 raises the question of what it means to attend a meeting from a distance when most team members are in the same physical space. Compared to their normal meeting setting - a group-to-group meeting in which all the teams are "distributed" from one another- the setting in Vienna led to stronger bonds between the co-located participants by putting the few distributed team members in the situation of being "on a screen far away". Figures $2 \mathrm{a}$ and $2 \mathrm{~b}$ illustrate the setting in Vienna.

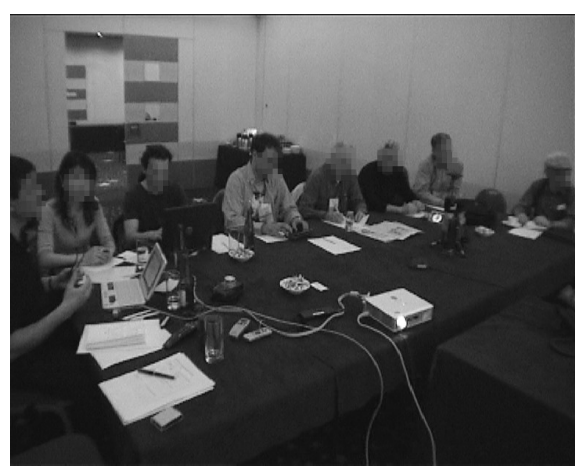

Fig. 2a. Team members sitting in the same location

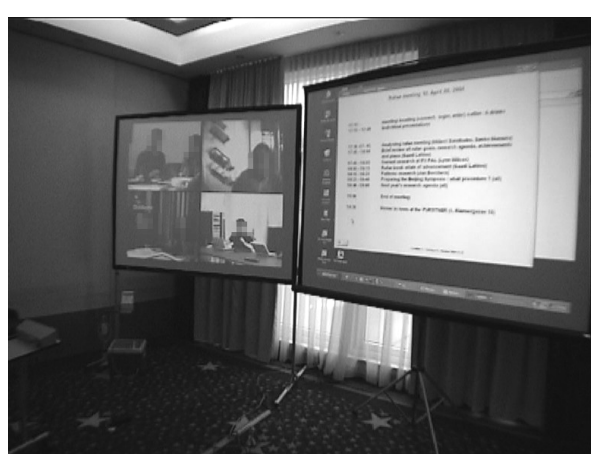

Fig. 2b. View of the other teams and of the shared media space 
In the Vienna meeting we identified two phenomena that arose from the participants' situation at the meeting. It is important to note, and we will return to this, that these phenomena are not exclusive to the situation in Vienna. The first phenomenon is implicit excluding: without anyone intending to exclude the distributed participants from the co-located team members it can happen anyway (cf. [8] who talk about 'collocation blindness'). Sometimes it happens because the colocated participants share something that is hard or impossible to transfer over the video link; for example, the co-located participants in Vienna talked about the dinner they would attend that evening. Another example, as we saw in Excerpt 4, is that colocated participants started to have more intensive local discussions (lines 2 and 7); though they were short, 2 and 5 seconds respectively, they excluded the distributed team members. In that sense we might say that the situation is fairer when all the teams are distributed: the risk of being implicitly excluded is reduced, or equal, for everybody. On the other hand, we have seen in our data and illustrated in Excerpt 2, there is also the risk of being excluded in this more "equal" situation. Being invisible is certainly a disadvantage in this complex meeting situation, and the implication is that all teams need to be visible to the others.

One way to overcome some of these limitations in the system is the chair's active effort to include the others. This leads us to the second characteristic: explicit including. By explicit including we mean that it is easier for someone to make a successful turn (i.e. a response or a weak initiative) if someone else has already made a strong initiative to include them in the discussion (as we saw in Excerpts 1 and 2). Again this is especially evident when most of the group is gathered together and only a few team members are "distributed". In the data from the April meeting we saw only a few initiatives by the distant team members that succeeded without a direct request - thus, an explicit including. Also, team members who tried to contribute to the conversation rarely succeeded after the first try, a phenomenon we do not have space to illustrate here. One team member, who was connected in the videoconference, also stressed this problem a couple of times during the meeting. This shows how the distributed team members experienced what [28] describe as the "space between".

\section{Discussion}

Participants' ways of communicating and interacting in geographically distributed meetings are constrained by the available media as well as the composition of the media. We have seen in this study that the mix of video and audio conferencing added considerable complexity to the meeting situation (see also [37]). In this paper we have described some techniques and conventions that the team members developed to handle the situation and overcome some difficulties. To better understand the aspects of being distributed versus co-located we have paid special attention in this analysis to a meeting - the one in Vienna-where most team members were co-located. Identifying the implicit excluding and explicit including helps us to understand the team members' situation during the meetings.

At the Vienna meeting we saw that it was difficult for the few persons participating on video to enter into the discussion. This led us to what we call implicit excluding, 
that is being excluded without anyone intending that to happen. The local chats in Excerpt 4, of 2 and 5 seconds respectively, also show how the distributed team members were excluded. Similarly [1] showed that turning off the video and/or audio may make distributed participants feeling excluded. To understand why this happens we must remember that the participants in the face-to-face situation have the advantage of being part of the 'principal setting' [10] and that those participating from a distance are part of what can be seen as a 'derivative' of that setting (cf. [6], p. 43), which therefore requires particular management techniques and practices [10]. Correspondingly, in their habitual setting with group-to-group collaboration, we have seen how those participating by audio only have the disadvantage of not being seen; in this setting the audio only mode could be seen as the derivative of the principal setting of the video and audio mode. This can explain why the persons on audio find it hard to join into the conversation, and have the need of being introduced and reintroduced if they are not to be totally forgotten; that is to say, they need to be explicitly included. This is also the reason why the group has developed the convention of having the chair introduce all participating teams, no matter the mode, at the very beginning of the meeting. Clearly, an ideal system would communicate the presence of all the team members.

Another social convention they have developed over time is that those who are not speaking turn off their microphones. This convention was developed explicitly to minimize disturbances during the meeting, but it led to a new behavior: now people can talk to their local colleagues at the same time that they are part of the network activities. In Excerpt 3 we identified one outcome of this new behavior: a parallel local discussion led to a quicker decision for the team as a whole. This shows that it is possible to make faster decisions when using computer-mediated communication, an opposite result to what [4] have found. It also illustrates how the meeting space supports the group decision process as well as the division of labor in a way that would not be possible in a co-located meeting. The set-up makes it possible for the team members to communicate and interact with each other in several ways in parallel: with the team members in the common discussion, with the co-located team members, and with individual distributed team members through the IM. In this way different networks may co-exist [28].

The next step we plan to take is to look at how this kind of setting, with large displays and shared tools, impacts the roles the team members take on. We will look at both this corpus with distributed collaboration and another corpus with co-located work (described earlier in $[38,39]$ ). In the distributed setting we have seen that the roles become accentuated [37], and that certain constraints make it more or less plausible to make successful initiatives like those reported on here. In contrast, in the co-located setting we saw indications of how the workspace helps to equalize the roles between the team members [38]. We will also continue to investigate implicit excluding and explicit including since we think that these phenomena will help us improve the design of systems for distributed collaboration.

Acknowledgement. This work was partly sponsored by EDF R\&D and the European Commission through a Marie Curie Fellowship in Social Representation and Communication. I want to thank Jakob Tholander for valuable comments on an earlier 
draft and Michael Baker for fruitful discussions regarding the analysis. Finally I thank the researchers in the RUFAE network who have allowed me to observe and take part in their meetings.

\section{References}

1. Abel, M.: Experiences in an Explanatory Distributed Organization. In: Galegher, J., Kraut, E.K., Egido, C. (eds.) Intellectual Teamwork: Social and Technological Foundations of Cooperative Work, pp. 489-510. Lawrence Erlbaum Associates, Hillsdale, NJ (1990)

2. Baker, M., Andriessen, J., Lund, K., van Amelsvoort, M., Quignard, M.: Rainbow: A Framework for Analysing Computer-Mediated Pedagogical Debates. Submitted to the International Journal of Computer-Supported Collaborative Learning (submitted)

3. Baker, M.J., Quignard, M., Lund, K., Séjourné, A.: Computer-supported collaborative learning in the space of debate. In: Wasson, B., Ludvigsen, S., Hoppe, U. (eds.) Designing for Change in Networked Learning Environments: Proceedings of the International Conference on Computer Support for Collaborative Learning 2003, pp. 11-20. Kluwer Academic Publishers, Dordrecht (2003)

4. Baltes, B.B., Dickson, M.W., Sherman, M.P., Bauer, C.C., LaGanke, J.S.: ComputerMediated Communication and Group Decision Making: A Meta-Analysis. Organizational Behavior and Human Decision Processes 87, 156-179 (2002)

5. Becker, B., Mark, G.: Social Conventions in Collaborative Virtual Environments. In: Churchill, E., Snowdon, D. (eds.) Proceedings of CVE'98: Collaborative Virtual Environments, Manchester (1998)

6. Berger, P., Luckmann, T.: The Social Construction of Reality: A Treatise in the Sociology of Knowledge. Doubleday, New York (1966)

7. Bradner, E., Mark, G.: Why Distance Matters: Effects on Cooperation, Persuasion and Deception. In: Proceedings of the Conference on Computer Supported Cooperative Work, pp. 226-235. ACM Press, New York (2002)

8. Bos, N., Olson, J., Nan, N., Shami, N.S., Hoch, S., Johnston, E.: 'Collocation blindness' in Partially Distributed Groups: Is There a Downside to Being Collocated? In: Proceedings of the SIGCHI conference on Human Factors in Computing Systems, pp. 1313-1321. ACM Press, New York (2006)

9. Bos, N., Shami, N.S., Olson, J.S., Cheshin, A., Nan, N.: In-group/Out-group Effects in Distributed Teams: An Experimental Simulation. In: Proceedings of the Conference on Computer Supported Cooperative Work, pp. 429-436. ACM Press, New York (2004)

10. Clark, H.H.: Using Language. Cambridge University Press, Cambridge, UK (1996)

11. Erickson, F., Schultz, J.: When is a Context? Some Issues and Methods in the Analysis of Social Competence. In: Cole, M., Engeström, Y., Vasquez, O. (eds.) Mind, Culture and Activity, pp. 22-31. Cambridge University Press, Cambridge, UK (1997)

12. Gaver, W.W., Sellen, A., Heath, C., Luff, P.: One is Not Enough: Multiple Views in a Media Space. In: Proceedings of the SIGCHI conference on Human Factors in Computing Systems, pp. 335-341. ACM Press, New York (1993)

13. Gay, G., Hembrooke, H.: Activity-Centered Design: An ecological approach to designing smart tools and usable systems. MIT Press, Cambridge, MA (2004)

14. Geyer, W., Richter, H., Fuchs, L., Frauenhofer, T., Daijavad, S., Poltrock, S.: A team collaboration space supporting capture and access of virtual meetings. In: Proceedings of the 2001 International ACM SIGGROUP Conference on Supporting Group Work, pp. 188-196. ACM Press, New York (2001) 
15. Gergle, D., Kraut, R.E., Fussell, S.R.: Action as Language in a Shared Visual Space. In: Proceedings of the Conference on Computer Supported Cooperative Work, pp. 487-496. ACM Press, New York (2002)

16. Goffman, E.: The Presentation of Self in Everyday Life. Doubleday, New York (1959)

17. Hindus, D., Ackerman, M., Mainwaring, S.D., Starr, B.: Thunderwire: A Field Study of an Audio-Only Media Space. In: Proceedings of the Conference on Computer Supported Cooperative Work, pp. 238-247. ACM Press, New York (1996)

18. Isaacs, E.A., Morris, T., Rodriguez, T.R.: A forum for supporting interactive presentations to distributed audiences. In: Proceedings of the Conference on Computer Supported Cooperative Work, pp. 405-416. ACM Press, New York (1994)

19. Isaacs, E., Tang, J.C.: What Video Can and Cannot Do For Collaboration: A Case Study. Multimedia Systems 2(2), 63-73 (1994)

20. Korolija, N., Linell, P.: Episodes: Coding and Analyzing Coherence in Multiparty Conversation. Linguistics 34, 799-831 (1996)

21. Jordan, B., Henderson, A.: Interaction Analysis: Foundations and Practice. The Journal of the Learning Sciences 4(1), 39-103 (1995)

22. Kraut, E.K., Egido, C., Galegher, J.: Patterns of Contact and Communication in Scientific Research Collaborations. In: Galegher, J., Kraut, E.K., Egido, C. (eds.) Intellectual Teamwork: Social and Technological Foundations of Cooperative Work, pp. 149-171. Lawrence Erlbaum Associates, Hillsdale, NJ (1990)

23. Lahlou, S.: Observing Cognitive Work in Offices. In: Streitz, N.A., Konomi, S., Burkhardt, H.-J. (eds.) CoBuild 1998. LNCS, vol. 1370, pp. 150-163. Springer, Heidelberg (1998)

24. Lewis, D.K.: Convention: A Philosophical Study. Harvard University Press, Cambridge (1969)

25. Liao, C., Liu, Q., Kimber, D., Chiu, P., Foote, J., Wilcox, L.: Shared Interactive Video for Teleconferencing. In: Proceedings of ACM Multimedia 2003, pp. 546-554. ACM Press, New York (2003)

26. Linell, P., Gustavsson, L., Juvonen, P.: Interactional Dominance in Dyadic Communication: A Presentation of Initiative-Response Analysis. Linguistics 26, 415-442 (1988)

27. Mark, G.: Conventions and commitments in distributed groups. Computer Supported Cooperative Work: The Journal of Collaborative Computing 11(3-4), 349-387 (2002)

28. Mark, G., Abrams, S., Nassif, N.: Group-to-Group Distance Collaboration: Examining the "Space Between". In: Proceedings of the Conference on Computer Supported Cooperative Work, pp. 99-118. Kluwer Academic Publ., Dordrecht (2003)

29. Neale, D.C., Carroll, J.M., Rosson, M.B.: Evaluating Computer-Supported Cooperative Work: Models and Framworks. In: Proceedings of the Conference on Computer Supported Cooperative Work, pp. 112-121. ACM Press, New York (2004)

30. Pomerantz, A., Fehr, B.J.: Conversation Analysis: An Approach to the Study of Social Action as Sense Making Practices. In: van Dijk, T.A. (ed.) Discourse as Social Interaction, pp. 64-91. Sage Publications, London (1997)

31. Rogers, Y., Brignull, H., Scaife, M.: Designing Dynamic Interactive Visualisations to Support Collaboration and Cognition. In: Proceedings of 1st International Symposium on Collaborative Information Visualization Environments, pp. 39-50. IEEE, London (2002)

32. Rosenberg, D., Foley, S., Kammas, S., Lievonen, M.: Interaction space theory: A framework for tool development. In: Proceedings of the 1st International Symposium on Information and Communication Technologies, pp. 427-432 (2003) 
33. Schön, D.A.: The Reflective Practitioner: How Professionals Think in Action. Basic Books, New York (1991)

34. Simone, C., Divitini, M., Schmidt, K.: A notation for malleable and interoperable coordination mechanisms for CSCW systems. In: The Proceedings of the Conference on Organizational Computing Systems, pp. 44-54. ACM Press, New York (1995)

35. Sinclair, J.McH., Coulthard, M.: Towards an Analysis of Discourse: The English Used by Teachers and Pupils. Oxford University Press, London (1975)

36. Suchman, L.: Plans and Situated Actions: The Problem of Human-Machine Communication. Cambridge University Press, Cambridge, USA (1987)

37. Sundholm, H.: To Share or Not to Share: Distributed Collaboration in Interactive Workspaces. In: Hassanaly, P., Herrmann, T., Kunau, G., Zacklad, M. (eds.) Cooperative Systems Design: Seamless Integration of Artifacts and Conversations - Enhanced Concepts of Infrastructure for Communication, pp. 270-285. IOS Press, Amsterdam (2006)

38. Sundholm, H., Artman, H., Ramberg, R.: Backdoor Creativity: Collaborative Creativity in Technology Supported Teams. In: Darses, F., Dieng, R., Simone, C., Zacklad, M. (eds.) Cooperative Systems Design: Scenario-based Design of Collaborative Systems, pp. 99114. IOS Press, Amsterdam (2004)

39. Sundholm, H., Ramberg, R., Artman, H.: Learning Conceptual Design: Activities with Electronic Whiteboards. In: Agger Eriksen, M., Malmborg, L., Nilsen, J. (eds.) CADE2004 Web Proceedings of Computers in Art and Design Education Conference, Copenhagen Business School, Denmark and Malmö University, Sweden (2004), asp.cbs.dk/cade2004/proceedings/

40. Veinott, E.S., Olson, J., Olson, G.M., Fu, X.: Video Helps Remote Work: Speakers Who Need to Negotiate Common Ground Benefit from Seeing Each Other. In: Proceedings of the SIGCHI conference on Human Factors in Computing Systems, pp. 302-309. ACM Press, New York (1999)

41. Yankelovich, N., Walker, W., Roberts, P., Wessler, M., Kaplan, J., Provino, J.: Meeting Central: Making Distributed Meetings more Effective. In: Proceedings of the Conference on Computer Supported Cooperative Work, pp. 419-428. ACM Press, New York (2004) 